\title{
Effects of Scaffolding Creative Problem Solving through Question Prompts in Project-Based Community Service Learning
}

\section{Prof. Wei Zheng, Jackson State University}

Dr. Wei Zheng is an associate professor of Civil Engineering at Jackson State University. He received his Ph.D. in Civil Engineering from University of Wisconsin-Madison in 2001 and has over ten years of industrial experience. Since becoming a faculty member at JSU in 2005 , he has made continuous efforts to integrate emerging technologies and cognitive skill development into engineering curriculum.

\section{Mr. Yanhua Cao, Jackson State University}

Yanhua Cao is an doctoral candidate in Education. He is interested in the research of cyber learning and collaborative learning. 


\title{
Effects of Scaffolding Creative Problem Solving through Question Prompts in Project-Based Community Service Learning
}

\begin{abstract}
This paper presents impacts of a proposed instructional framework of scaffolding creative problem solving through question prompts in project-based community service learning on students' learning dispositions and outcomes. The presented results were obtained based on analysis of the collected data from students in the past implementation. The participants were freshmen from a historical black university, who were registered in a general entry course that requires the community service. Through different delivery methods - seminar (or traditional lecture), online learning materials, and online materials with emailed prompts, the scaffolding was provided to participants as additional course instructions with meta-cognitive prompts, procedural prompts, elaboration prompts, and reflective prompts, as well as prompts of creative problem solving strategies. While a previously published ASEE conference paper reported the correlations among application of question prompts, students' learning process and learning outcomes of their project-based community service learning based on collected students' learning data, this paper reveals impacts of the scaffolding through different delivery approaches on students' perceptions on creative problem solving, self-efficacy, identity, and application of creativity strategies. It also confirms the correlation among application of prompts and students' learning process and learning outcomes, and compares the available results of data analysis from two implementation years. The results from data analysis indicate that scaffolding creative problem solving through freshmen's project-based service learning may in general enhance student's self-efficacy, strategies application, and interest in engineering. Among three intervention approaches, the traditional seminar approach to introducing creative strategies and question prompts may particularly promote students to apply cognitive strategies and questions prompts and enhance their confidence in their ability. The online learning of creative strategies and question prompts may be more effective in scaffolding students' learning process and enhancing students' learning outcomes. The online learning with emailed prompts may be more effective in fostering students' self-efficacy and learning of methodology, and strengthening their interest in creativity and engineering, as well as their career identity.
\end{abstract}

\section{Introduction}

Nurturing creativity and metacognitive skills of undergraduate students is critical for U.S. to maintain its global competitiveness, economic prosperity, and security. Creativity is defined by some cognitive researchers as the introduction of new variables, significant leaps, or novel connection, and is a process resulting in a novel products ${ }^{1,2}$. Torrance concluded three characteristics of creativity: originality, idea fluency, and flexibility, and claimed that every person has his or her creativity and that creativity could be cultivated ${ }^{3}$. Amabile established a psychological model of creativity that includes four factors: intrinsic motivation, domain knowledge, creative skills, and environment ${ }^{4}$. Metacognition refers to the awareness of and reflection on one's learning process and is higher-order mental processes ${ }^{5,6}$. Metacognition includes making plans for learning and applying appropriate strategies to acquire information, solve problem, and evaluate the result and the process of learning ${ }^{6}$. Metacognition consists of two main components: metacognitive knowledge and metacognitive experiences ${ }^{7}$. Previous studies have proved that metacognitive training can significantly improve students’ academic performance ${ }^{8,9}$. 
Creative problem solving skills can be defined as an approach to innovatively identify and solve problems and are frequently emphasized in engineering design. The process of engineering design can be described as repeated cycles of a multiple-phase model: defining the problem, gathering pertinent information, generating multiple solutions, analyzing and selecting a solution, and testing and implementing the solution. Thus, engineering design is frequently employed to foster students' creativity development ${ }^{10,11,12}$. Cropley demonstrated the effectiveness of lectures on creativity in promoting students' innovation in the machine $\operatorname{design}^{13}$.

Many faculty members have recognized the importance of creative problem solving skills. However, they may not know and adopt the findings from educational research on such skill development into their course instructions to foster creativity and metacognitive skill development for their students, or may not have opportunity to provide explicitly such instruction for nurturing this skill development due to limited time and over-packed course contents. As a result, traditional education in science, technology, engineering, and mathematics (STEM) usually overemphasized on memorization of knowledge and procedures rather than higher-order thinking skills, such as creative problem skills ${ }^{14}$. Most students did not receive explicit instructions on development of creativity and metacognitve skills from their instructors in their major courses ${ }^{15}$.

The problem-based service learning (PBSL) may offer unique opportunities different from the traditional learning for students to face real world problems that may demand innovative solution through creative problem solving processes. Thus, the PBSL may be utilized as a platform to develop creativity and metacognitive skills of students. Nevertheless, students may not spontaneously develop their creative problem solving skills or may not know how to effectively develop innovative solution. Thus, the instructional support or scaffolding may be provided to students to provoke or guide their creative problem solving processes, particularly in their PBSL. A commonly used scaffolding method for indirectly guiding the assessment and regulation of learners' learning and problem solving processes is prompts $^{16}$. Rosenshine and Meister proved the advantages of the use of question prompts in directing students' attention to important aspects of the problem, activating their schema, eliciting their explanations, and prompting them for self-monitoring and self-reflection ${ }^{17}$. Davis and Linn also found that reflective prompts nurtured students' knowledge integration and encouraged reflection ${ }^{18}$.

Even though there are many claimed beneficial outcomes for students from the projectbased service learning (PBSL), there is limited research that provides data-based evidence to support these claims. McCormick et al. ${ }^{19}$ had made prior efforts in this area and first conducted experimental studies to test the hypothesis that PBSL can serve as a mechanism that can allows students to develop the necessary problem solving skills. Their studies used four-open-ended questions to evaluate the analytical skills, practical skills, creative skills of students who participated in PBSL ( $=11)$ and compared them with those of students who did not participated in PBSL ( $\mathrm{N}=33$ ). The test results indicate that students with the PBSL experience had a higher skills level than those who have not had a PBSL. However, they suggested that the conclusion from their studies required further evaluation on larger sample with more diverse group of students, and further research should also identify if the amount experience and the students' personal background play significant roles that affects the test results ${ }^{19}$. 
While a previously published ASEE conference paper reported the certain correlations among students' application of question prompts, and their learning process and learning outcomes of the project-based community service learning based on the first year implementation $^{20}$, this paper attempts to reveal impacts of scaffolding creative problem solving through question prompts on students' perception on creative problem solving, selfefficacy, identity, and application of creative strategies based on data collected from the subsequent year implementation. This extended work furthered the existing correlation analysis of scaffolding creative problem solving through question prompts. This work is continuously conducted among freshmen within a historical black university. It is expected that its findings may offer useful guideline for the education practice through PBSL for fostering creative problem solving skills with those minority students.

Table 1 Research Participants for Intervention in the Freshmen Service Learning Per Year

\begin{tabular}{l|c|c|c|c|c}
\hline \multirow{2}{*}{ Student Group } & \multicolumn{2}{|l|}{ Treatment } & \multicolumn{2}{l}{$\begin{array}{l}\text { Question prompt } \\
\text { repository }\end{array}$} & e-mailed prompts \\
\cline { 2 - 6 } & Service learning & Seminar & Online learning & \\
\hline $\mathrm{A}($ Control) & $\mathrm{x}$ & $\mathrm{x}$ & & $\mathrm{x}$ & \\
\hline $\mathrm{B}($ Intervention) & $\mathrm{x}$ & $\mathrm{x}$ & $\mathrm{x}$ & $\mathrm{x}$ & $\mathrm{x}$ \\
\hline $\mathrm{D}($ Intervention) & $\mathrm{x}$ & & $\mathrm{x}$ & $\mathrm{x}$ & \\
\hline
\end{tabular}

\section{Methodology}

The research was carried out at a historically black university where about $90 \%$ of students are African American. All students registered in an entry-level course - University Success 100 at authors' institution were required to participate in community service. The research participants were students from several selected courses of University Success 100, whose instructors agreed to adopt the proposed scaffolding as additional instructions for their courses. As a part of course assignment, the students from those courses were required to identify the problem needed to be solved in their community service sites, collaborate with their team members, design innovative solutions to the problems, and evaluate and reflect the process in their community service learning projects. In 2013 implementation, totally 9 classes consisting of 411 students were involved. Each class was randomly assigned into one of four groups and provided with scaffoldings through different approaches except the classes assigned as a control group. Those students' participation in the self-report survey is voluntary. The research plan was reviewed and approved by the IRB at the authors' institution.

Thus, four groups of classes were formed with the same requirement for service learning project and different instruction approaches as shown in Table 1. This aimed to make the intervention easily implemented and collect more valid data. All Students in the course were provided with printed copies of community service learning project requirements and grading criterions. The project assignment required students to write their learning journals to help them review their thinking process and reveal their application of creative thinking skills in the process of their community service learning, and complete their final project reports to present their projects. Detailed requirements for the problem-based service learning can be retrieved from the previously published ASEE conference paper by Zheng et al. ${ }^{20}$

The different types of scaffolding were provided to students in different class sessions during the period of their community service learning over the fall semester. The different scaffolding is shown in Table 1. The Group A was control group and was not provided with 
no scaffolding. The Group B was provided with one seminar and the printed handouts on how to think creatively in their study and daily life, as well as question prompts for creative problem solving. The Group $\mathrm{C}$ provided with the online reading materials, which was the same as those printed handouts provided for the Group B. The group D received the online materials same as those provided to the Group B, as well as regular e-mails on the question prompts sent by the research team to remind students to use those prompts during their service learning process. The provided question prompts included metacognitive, procedural elaboration, reflective and creative problem solving prompts, which can be found in the previously published ASEE conference paper by Zheng et al. ${ }^{20}$

\section{Data collection and results from data analysis}

The presented data were obtained through students' self-report surveys, as well as students' learning journals and project reports submitted to instructors. Those self-report surveys were developed by authors based on various accepted instruments, and asked students to rate each survey item in the 1-5 Likert scale. Those survey items can be found from the result tables in the subsequent sections, including those on students' perception related to creativity and their learning creativity in both the pre-test phase and the post-test phase, as well as those on students' satisfaction and utilization of question prompts for selfregulated learning and creative problem in the post-test phase. In addition, students were surveyed on their preferred approaches and formats for delivering the scaffolding in the posttest phase. A rubric had been developed for coding the collected learning process journals and project reports ${ }^{20}$. The coding results were used for assessing students' process and outcomes of creative problem solving in their project-based service learning project.

\subsection{Perception change among students from the intervention group and control group}

Students' perception change was measured by the difference between the pretest and the posttest and analyzed by using T-test. Results from the analysis are tabulated in Table 4.1-1 and Table 4.1-2 for the invention group and the control group respectively. Comparisons between the pretests and posttests of the perception survey of the intervention groups (Group B, C, and D) showed that (see Table 4.1-1) there were increase with a statistical significance in two survey items: "Learned creativity in class" and "Self-awareness of creativity strategies" with the effect size of 0.19 and 0.33 , while there were not such significant increase for students in the control group (see Table 4.1-2). Those results indicate the proposed interventions through question prompts have the positive impacts on students' learning creativity and their awareness of creativity strategies. It also be noted that the students in the intervention groups indicate the increase of their perception on "methodology and strategies" of creativity and "utilizing creativity strategies", while the students in the control group experienced no change or even decrease in those two measurements respectively. This may also indicate the potential positive impacts of the intervention on students.

Comparison between the intervention groups and control group also indicate that students from both groups experienced the decrease with a statistical significance in their perception of their improved creativity. This may suggest that the proposed intervention through 
question prompts might not have impact on students' perception on their increased creativity. Furthermore, students in the intervention groups demonstrated the increase with a statistical significance in their perception on "Fixed intelligence", while the students in the control group did not change significantly in this measurement. This may imply that the intervention might have the impact of enhancing students' belief that the intelligent is fixed and inborn and can not be changed.

Students in intervention groups reported the increase in "learned creativity in class" and "self-awareness of creativity strategies". On other hand, they indicated their decrease in "creativity improvement with instruction", and their increase in "Belief in fixed intelligence". Those results seem contradict, but actually can be consistent. This can be explained as follows: if some students found these creativity strategies were beyond their capacity and can not be mastered, they might become more believed in fixed intelligence. If other students found that these creativity strategies were easy for them, their expectations for learning might not be met. Both cases could lead to the decrease in their perception of "creativity improvement with instruction" and increase in their "belief in fixed intelligence".

Table 4.1-1 Comparisons between pretest and posttest in the perception survey for intervention groups $(n=183)$

\begin{tabular}{|c|c|c|c|c|c|c|}
\hline \multirow[b]{2}{*}{ Factors } & \multicolumn{2}{|c|}{ Pretest } & \multicolumn{2}{|c|}{ Posttest } & \multirow[b]{2}{*}{ Effect size } & \multirow[b]{2}{*}{$\mathrm{t}$} \\
\hline & M1 & SD1 & M2 & SD2 & & \\
\hline 1.Interests in engineering & 2.40 & 1.48 & 2.44 & 1.51 & 0.02 & 0.42 \\
\hline 2.Pursuing engineering & 2.27 & 1.54 & 2.34 & 1.59 & 0.04 & 0.99 \\
\hline 3.Creative person & 3.92 & 0.94 & 3.99 & 0.97 & 0.07 & 1.05 \\
\hline 4.Knowing about creativity & 3.99 & 0.90 & 4.25 & 2.33 & 0.11 & 1.41 \\
\hline 5.Taught creativity in class & 3.47 & 1.10 & 3.60 & 1.12 & 0.12 & 1.51 \\
\hline 6.Learned creativity in class & 3.43 & 1.13 & 3.64 & 1.07 & 0.19 & $2.29 *$ \\
\hline 7.Creativity improvement with instruction & 4.15 & 0.99 & 3.95 & 1.03 & -0.20 & $-2.29 *$ \\
\hline 8.Methodology and strategies & 3.26 & 1.13 & 3.41 & 1.09 & 0.14 & 1.56 \\
\hline 9.Importance of creativity & 4.21 & 1.07 & 4.11 & 1.07 & -0.09 & -1.10 \\
\hline 10.Utilizing creativity strategies & 3.78 & 0.94 & 3.90 & 1.00 & 0.12 & 1.34 \\
\hline 11.Self awareness of creativity strategies & 2.61 & 1.30 & 3.05 & 1.31 & 0.33 & $3.56^{* *}$ \\
\hline 12.Belief in fixed intelligence & 2.05 & 1.38 & 2.76 & 1.67 & 0.42 & $5.06 * *$ \\
\hline
\end{tabular}

Note: only changes with * have statistical significance 
Table 4.1-2 Comparisons between the pretest and posttest in perception survey for the control group $(n=31)$

\begin{tabular}{lllllll}
\hline & Pretest & \multicolumn{3}{c}{ Posttest } & & \\
\cline { 2 - 6 } Factors & M1 & SD1 & M2 & SD2 & Effect size & t \\
\hline 1.Interests in engineering & 2.16 & 1.46 & 2.32 & 1.51 & 0.07 & 0.82 \\
2.Pursuing engineering & 2.06 & 1.48 & 2.19 & 1.47 & 0.06 & 0.78 \\
3.Creative person & 4.16 & 0.86 & 4.26 & 0.89 & 0.02 & 0.65 \\
4.Knowing about creativity & 3.97 & 0.71 & 4.97 & 5.30 & 0.25 & 1.02 \\
5.Taught creativity in class & 3.55 & 1.21 & 3.74 & 1.06 & 0.05 & 1.14 \\
6.Learned creativity in class & 3.45 & 1.31 & 3.71 & 1.19 & 0.07 & 1.35 \\
7.Creativity improved & 4.32 & 0.91 & 3.81 & 1.05 & -0.12 & $-2.63^{* *}$ \\
8.Methodology and strategies & 3.29 & 1.07 & 3.23 & 1.12 & -0.02 & -0.36 \\
9.Importance of creativity & 4.13 & 1.12 & 3.87 & 1.28 & -0.06 & -1.25 \\
10.Utilizing creativity strategies & 3.94 & 0.85 & 3.94 & 1.03 & 0.00 & 0.00 \\
11. Self awareness of creativity strategies & 2.32 & 1.38 & 2.39 & 1.28 & 0.03 & 0.27 \\
12. Belief in fixed intelligence & 1.84 & 1.27 & 2.39 & 1.61 & 0.30 & 1.53
\end{tabular}

Note: only changes with * have statistical significance

\subsection{Impacts from different interventions}

Students' perception change for each intervention groups was measured by the difference between pre-test and post-test and analyzed by using T-test. Results from the analysis are tabulated in Table 4.1-3, 4.1-4, and Table 4.1-5 below for the seminar group, online learning group, and online learning and e-mail reminder group respectively.

Results in Table 4.1-3 demonstrate that the perception changes of students in the seminar group have slightly negative effect size after the seminar intervention. However, students' perception of "methodology and strategies" and "importance of creativity" decreased significantly, while the growth in the perception of "belief in fixed intelligence" was significant. It indicates that most students did not think they gained knowledge of creativity and engineer design approach from the seminar, but they believed more in fixed intelligence.

As indicated in Table 4.1-4, students in the online learning group showed significant increase in their perception of themselves as a "creative person", "knowing about creativity". They also demonstrated significant growth in their perception on "learned creativity in class", knowledge of “methodology and strategies”, "self-awareness”. In addition, some other factors also had the positive effect size, such as "interests in engineering”, "taught creativity in class", "importance of creativity", and "utilizing creativity strategy". Those results indicate that online intervention may be effective in helping students gain knowledge of creativity and utilizing creativity strategies in comparing with the seminar group. However, they also indicated that their increased "belief in fixed intelligence" with a statistical significance.

For the Group of Online Learning with E-mailed Prompts (Group D), Table 4.1-5 shows that the scores on students' perceptions of "learned creativity in class", "methodology and strategies”, "self-awareness” in posttest was significantly larger than those in pretest for Group D in the similar way as those shown in the online learning group (Group C), but have 
even lager effects on them than those in Group C. The results in Table 4.1-5 also indicated significant increase in students' perception of "utilizing creativity strategy", which is not demonstrated among the students in the in the online learning group (Group C). However, students in Group D did not indicate any significant increase in their perception of being "creative person" as the students in the online group did. They may even show the increased "belief in fixed intelligence".

Table 4.1-3 Comparisons between the pretest and posttest in perception survey for the seminar group $(n=58)$

\begin{tabular}{lllllll}
\hline & \multicolumn{7}{c}{ Pretest } & \multicolumn{3}{c}{ Posttest } \\
\cline { 2 - 5 } Factor & M1 & SD1 & M2 & SD2 & Effect size & t \\
\hline 1.Interests in engineering & 2.02 & 1.26 & 2.10 & 1.31 & 0.07 & 0.63 \\
2.Pursuing engineering & 1.90 & 1.29 & 2.00 & 1.45 & 0.07 & 0.79 \\
3.Creative person & 3.90 & 0.93 & 3.83 & 1.05 & -0.07 & -0.51 \\
4.Knowing about creativity & 3.98 & 0.91 & 3.93 & 0.95 & -0.05 & -0.39 \\
5.Taught creativity in class & 3.50 & 1.10 & 3.47 & 1.06 & -0.03 & -0.25 \\
6.Learned creativity in class & 3.53 & 1.11 & 3.45 & 0.98 & -0.09 & -0.52 \\
7.Creativity improved & 4.09 & 0.98 & 4.10 & 0.95 & 0.02 & 0.11 \\
8.Methodology and strategies & 3.33 & 1.11 & 2.97 & 1.01 & -0.36 & $-2.03^{*}$ \\
9.Importance of creativity & 4.33 & 1.03 & 4.00 & 1.14 & -0.29 & $-2.05^{*}$ \\
10.Utilizing creativity strategies & 3.84 & 0.91 & 3.67 & 1.00 & -0.17 & -1.11 \\
11. Self awareness of creativity strategies & 2.78 & 1.35 & 2.83 & 1.29 & 0.04 & 0.20 \\
12. Belief in fixed intelligence & 2.12 & 1.34 & 2.60 & 1.58 & 0.31 & $2.13^{*}$ \\
\hline
\end{tabular}

Note: only changes with * have statistical significance

Table 4.1-4 Comparisons between pretest and posttest in perception survey for the online learning group $(n=55)$

\begin{tabular}{lllllll}
\hline & \multicolumn{7}{l}{ Pretest } & \multicolumn{3}{l}{ Posttest } & \\
\cline { 2 - 5 } Factors & M1 & SD1 & M2 & SD2 & Effect size t \\
\hline 1.Interests in engineering & 2.49 & 1.45 & 2.56 & 1.45 & 0.05 & 0.51 \\
2.Pursuing engineering & 2.33 & 1.49 & 2.27 & 1.55 & -0.04 & -0.43 \\
3.Creative person & 3.75 & 1.06 & 4.04 & 0.90 & 0.32 & $2.83^{* *}$ \\
4.Knowing about creativity & 3.85 & 1.03 & 4.24 & 0.90 & 0.42 & $2.66^{* *}$ \\
5.Taught creativity in class & 3.45 & 1.10 & 3.55 & 1.23 & 0.07 & 0.57 \\
6.Learned creativity in class & 3.38 & 1.08 & 3.71 & 1.08 & 0.30 & $2.07^{*}$ \\
7.Creativity improved & 4.07 & 0.98 & 3.93 & 1.02 & -0.14 & -0.98 \\
8.Methodology and strategies & 3.27 & 1.15 & 3.65 & 1.04 & 0.37 & $2.21^{*}$ \\
9.Importance of creativity & 4.04 & 1.14 & 4.24 & 0.94 & 0.21 & 1.35 \\
10.Utilizing creativity strategy & 3.73 & 0.97 & 4.00 & 0.94 & 0.29 & 1.77 \\
11. Self awareness of creativity strategies & 2.56 & 1.17 & 3.31 & 1.20 & 0.62 & $3.83^{* *}$ \\
12. Belief in fixed intelligence & 2.07 & 1.45 & 2.60 & 1.56 & 0.34 & $2.35^{*}$ \\
\hline
\end{tabular}

Note: only changes with * have statistical significance 
Table 4.1-5. Comparisons between pretest and posttest in perception survey for the group of online learning with e-mailed prompts $(n=39)$

\begin{tabular}{|c|c|c|c|c|c|c|}
\hline \multirow[b]{2}{*}{ Factors } & \multicolumn{2}{|c|}{ Pretest } & \multicolumn{2}{|c|}{ Posttest } & \multirow[b]{2}{*}{ Effect size } & \multirow[b]{2}{*}{$\mathrm{t}$} \\
\hline & M1 & SD1 & M2 & SD2 & & \\
\hline 1.Interests in engineering & 3.05 & 1.64 & 2.85 & 1.79 & -0.11 & -1.21 \\
\hline 2.Pursuing engineering & 2.90 & 1.82 & 3.05 & 1.78 & 0.09 & 0.92 \\
\hline 3.Creative person & 4.00 & 0.79 & 3.95 & 1.00 & -0.05 & -0.33 \\
\hline 4.Knowing about creativity & 4.23 & 0.81 & 4.15 & 0.90 & -0.09 & -0.68 \\
\hline 5.Taught creativity in class & 3.38 & 1.07 & 3.77 & 1.09 & 0.35 & 1.64 \\
\hline 6.Learned creativity in class & 3.33 & 1.11 & 3.77 & 1.09 & 0.40 & $2.07 *$ \\
\hline 7.Creativity improved & 4.21 & 1.08 & 3.85 & 1.16 & -0.31 & -1.74 \\
\hline 8.Methodology and strategies & 3.10 & 1.21 & 3.87 & 1.00 & 0.77 & $3.73^{* *}$ \\
\hline 9.Importance of creativity & 4.33 & 0.98 & 4.28 & 0.92 & -0.06 & -0.24 \\
\hline 10.Utilizing creativity strategy & 3.64 & 0.99 & 4.05 & 1.02 & 0.40 & $2.25^{*}$ \\
\hline 11.Self awareness & 2.67 & 1.36 & 3.54 & 1.27 & 0.68 & $3.35^{* *}$ \\
\hline 12. Belief in fixed intelligence & 2.10 & 1.47 & 3.51 & 1.82 & 0.78 & $4.03^{* *}$ \\
\hline
\end{tabular}

Note: only changes with * have statistical significance

Table 4.2-1.Comparisons between the seminar group and the online learning group in selfefficacy, identity and creativity after intervention

\begin{tabular}{lllllll}
\hline & \multicolumn{7}{l}{ Online learning } & \multicolumn{3}{l}{ Seminar } & \\
\cline { 2 - 5 } Factors & M1 & SD1 & M2 & SD2 & Effect size & t \\
\hline 1.Using cognitive strategies to learn & 3.30 & 1.09 & 3.39 & 1.14 & 0.08 & 0.49 \\
2.Using cognitive strategies to solve & 3.34 & 1.00 & 3.46 & 1.13 & 0.11 & 0.65 \\
3.Creativity thinking' role in academic & 3.55 & 0.92 & 3.71 & 0.97 & 0.17 & 0.99 \\
4.Better creativity, better academic & 3.92 & 0.95 & 3.75 & 1.01 & -0.17 & -0.99 \\
5.Using question prompts to solve & 3.50 & 1.04 & 3.68 & 1.02 & 0.18 & 1.01 \\
6.More confidence in ability & 3.80 & 0.88 & 3.96 & 0.95 & 0.17 & 1.01 \\
7.More clear beliefs in ability & 3.77 & 0.97 & 3.88 & 1.16 & 0.10 & 0.64 \\
8.Succeed to solve if using strategies & 4.45 & 3.74 & 4.12 & 0.98 & -0.34 & -0.72 \\
9.Remain calm facing difficulties & 3.78 & 0.95 & 3.83 & 0.98 & 0.05 & 0.27 \\
10.Confident dealing with problems & 3.77 & 0.99 & 3.88 & 0.83 & 0.14 & 0.75 \\
11. Adopting engineering approach & 3.27 & 1.21 & 3.00 & 1.18 & -0.23 & -1.28 \\
12. Wish to be engineering major & 2.84 & 1.53 & 2.35 & 1.42 & -0.35 & -1.93 \\
13. Professional identity & 2.64 & 1.40 & 2.51 & 1.43 & -0.09 & -0.54 \\
14. Career identity 1 & 2.44 & 1.49 & 2.14 & 1.39 & -0.21 & -1.17 \\
15. Interests in opinion for engineers & 2.64 & 1.44 & 2.35 & 1.38 & -0.21 & -1.20 \\
16. Belong to engineering & 2.45 & 1.47 & 2.19 & 1.52 & -0.17 & -1.02 \\
17. Career identity 2 & 2.39 & 1.42 & 2.09 & 1.40 & -0.22 & -1.24 \\
18. Engineer's honors & 2.75 & 1.43 & 2.30 & 1.49 & -0.30 & -1.76 \\
19. More interested in engineering & 2.67 & 1.46 & 2.26 & 1.43 & -0.29 & -1.64 \\
\hline
\end{tabular}

Note: the Seminar Group, n2=69, and the Online Learning Group, n1=64. 


\subsection{Impacts on Self-efficacy, Identity, and Application of Creativity Strategies}

The comparison of impacts on students' self-efficacy, identity, and application of creativity strategies among three interventions are shown in Table 4.2-1, Table 4.3-2, and Table 4.3-3. Table 4.2-1 demonstrates the comparison between the seminar and online learning groups, and indicates that there is not significant difference among the two groups. However, the online learning group had higher scores than the seminar group in "better creativity, better academic”, "succeed to solve if using strategies”, "professional identity”, “career identity”, “interests in opinion for engineers”, "belong to engineering”, "Engineer’s honors”, “adopting engineering approach”, “more interested in engineering”, and "wish to be engineering major". The results showed that the online learning might be more effective in strengthening students' interest in engineering and their career identity, while the seminar might enhance with students' application of cognitive strategies to learn and question prompts to solve problem, and increase their confidence in their ability.

Table 4.2-2 Comparisons between the seminar group and the group of online learning with emailed prompts in self-efficacy, identity and creativity after intervention

\begin{tabular}{lllllll}
\hline & \multicolumn{7}{l}{ online learning with e- } & & & \\
& \multicolumn{1}{l}{ mailed prompts } & \multicolumn{2}{l}{ Seminar } & & \\
\cline { 2 - 5 } Factors & M1 & SD1 & M2 & SD2 & Effect size & t \\
\hline 1.Using cognitive strategies to learn & 3.38 & 1.15 & 3.39 & 1.14 & 0.01 & 0.06 \\
2.Using cognitive strategies to solve & 3.49 & 1.12 & 3.46 & 1.13 & -0.02 & -0.12 \\
3.Creativity thinking' role in academic & 3.82 & 0.91 & 3.71 & 0.97 & -0.12 & -0.62 \\
4.Better creativity, better academic & 4.13 & 0.97 & 3.75 & 1.01 & -0.38 & $-2.00^{*}$ \\
5.Using question prompts to solve & 3.64 & 1.05 & 3.68 & 1.02 & 0.04 & 0.19 \\
6.More confidence in ability & 3.93 & 0.96 & 3.96 & 0.95 & 0.02 & 0.13 \\
7.More clear beliefs in ability & 3.71 & 1.01 & 3.88 & 1.16 & 0.15 & 0.82 \\
8.Succeed to solve if using strategies & 3.84 & 0.90 & 4.12 & 0.98 & 0.28 & 1.49 \\
9.Remain calm facing difficulties & 3.51 & 1.29 & 3.83 & 0.98 & 0.32 & 1.39 \\
10.Confident dealing with problems & 3.80 & 1.06 & 3.88 & 0.83 & 0.10 & 0.45 \\
11. Adopting engineering approach & 3.40 & 1.45 & 3.00 & 1.18 & -0.34 & -1.55 \\
12. Wish to be engineering major & 3.22 & 1.61 & 2.35 & 1.42 & -0.61 & $-3.05^{* *}$ \\
13. Professional identity & 2.98 & 1.60 & 2.51 & 1.43 & -0.33 & -1.64 \\
14. Career identity 1 & 2.67 & 1.43 & 2.14 & 1.39 & -0.38 & -1.94 \\
15. Interests in opinion for engineers & 3.58 & 4.89 & 2.35 & 1.38 & -0.89 & $-1.98^{*}$ \\
16. Belong to engineering & 2.62 & 1.54 & 2.19 & 1.52 & -0.29 & -1.48 \\
17. Career identity 2 & 2.56 & 1.53 & 2.09 & 1.40 & -0.33 & -1.68 \\
18. Engineer's honors & 2.84 & 1.52 & 2.30 & 1.49 & -0.36 & -1.88 \\
19. More interested in engineering & 2.82 & 1.57 & 2.26 & 1.43 & -0.39 & $-1.97^{*}$ \\
\hline
\end{tabular}

Note: the seminar group, $\mathrm{n} 2=69$, the online learning with e-mailed prompts group, $\mathrm{n} 1=45$.

The comparison between the seminar group and the group of online learning with e-mail prompts (see Table 4.2-2) demonstrate the significant difference in the measurements of "better creativity, better academic”, "wish to be engineering major”, and "'interest in opinion for engineers". Students in online learning group with e-mail prompts had significantly higher scores than those in the seminar group. The results also indicate that the online learning with e-mail prompts enhanced students' career identity and helped students understand the 
importance of creative thinking, while the seminar reinforced students' confidence in their ability and their application of cognitive strategies.

Even though the comparison between the online learning group and the group of online learning with e-mail prompts did not show significant difference, students in the group of online learning with e-mail prompts demonstrated higher scores in most measurements. The results particularly indicate that the online learning with e-mail prompts may exert more positive influence on students’ self-efficacy, identity, and creativity development.

Table 4.2-3 Comparisons between the seminar group and the group of online learning with emailed prompts in self-efficacy, identity and creativity after intervention

\begin{tabular}{lllllll}
\hline & \multicolumn{7}{c}{ online learning online learning with e-mailed } \\
\cline { 2 - 6 } Factors & M1 & SD1 & M2 & SD2 & Effect size & t \\
\hline 1.Using cognitive strategies to learn & 3.30 & 1.09 & 3.38 & 1.15 & 0.02 & 0.37 \\
2.Using cognitive strategies to solve & 3.34 & 1.00 & 3.49 & 1.12 & 0.04 & 0.71 \\
3.Creativity thinking' role in academic & 3.55 & 0.92 & 3.82 & 0.91 & 0.08 & 1.54 \\
4.Better creativity, better academic & 3.92 & 0.95 & 4.13 & 0.97 & 0.05 & 1.14 \\
5.Using question prompts to solve & 3.50 & 1.04 & 3.64 & 1.05 & 0.04 & 0.71 \\
6.More confidence in ability & 3.80 & 0.88 & 3.93 & 0.96 & 0.04 & 0.77 \\
7.More clear beliefs in ability & 3.77 & 0.97 & 3.71 & 1.01 & -0.01 & -0.28 \\
8.Succeed to solve if using strategies & 4.45 & 3.74 & 3.84 & 0.90 & -0.14 & -1.07 \\
9.Remain calm facing difficulties & 3.78 & 0.95 & 3.51 & 1.29 & -0.07 & -1.19 \\
10.Confident dealing with problems & 3.77 & 0.99 & 3.80 & 1.06 & 0.01 & 0.17 \\
11. Adopting engineering approach & 3.27 & 1.21 & 3.40 & 1.45 & 0.04 & 0.52 \\
12. Wish to be engineering major & 2.84 & 1.53 & 3.22 & 1.61 & 0.13 & 1.24 \\
13. Professional identity & 2.64 & 1.40 & 2.98 & 1.60 & 0.13 & 1.17 \\
14. Career identity 1 & 2.44 & 1.49 & 2.67 & 1.43 & 0.09 & 0.80 \\
15. Interests in opinion for engineers & 2.64 & 1.44 & 3.58 & 4.89 & 0.35 & 1.45 \\
16. Belong to engineering & 2.45 & 1.47 & 2.62 & 1.54 & 0.07 & 0.58 \\
17. Career identity 2 & 2.39 & 1.42 & 2.56 & 1.53 & 0.07 & 0.58 \\
18. Engineer's honors & 2.75 & 1.43 & 2.84 & 1.52 & 0.03 & 0.33 \\
19. More interested in engineering & 2.67 & 1.46 & 2.82 & 1.57 & 0.06 & 0.51 \\
\hline
\end{tabular}

Note: the online learning with e-mailed prompts group, $\mathrm{n} 2=45$, the online learning prompts group, $\mathrm{n} 1=64$.

\subsection{Impacts on students' satisfaction and learning experience}

Comparison of students' satisfaction and learning experience among three intervention groups are shown in Table 4.3-1 and Table 4.3-2. The comparison between the seminar group and online learning groups tabulated in Table 4.3-1 demonstrated that the seminar group gained more knowledge from question prompts, while the online group spent more time on guideline. The results imply that the online learning group might learn more through their self-regulated learning. The results in Table 4.3-2 implies that students in the group of online learning with e-mailed prompts understand more about the application of question prompts, while those in seminar group applied them more in the course learning. However, in general, there is no significant difference in students' satisfaction and learning experience on the presented instructional framework among three different intervention groups. 
Table 4.3-1 Comparisons between the seminar group and the online group in satisfaction after intervention

\begin{tabular}{lllllll}
\hline & Online & \multicolumn{5}{c}{ Seminar } \\
\cline { 2 - 6 } Factors & M1 & SD1 & M2 & SD2 & Effect size & $\mathrm{t}$ \\
\hline 1.Importance of question prompts & 3.59 & 0.85 & 3.77 & 0.91 & 0.19 & 1.14 \\
2.Usefulness of question prompts & 3.63 & 0.93 & 3.74 & 0.95 & 0.12 & 0.70 \\
3.Materials'organization & 3.66 & 0.82 & 3.78 & 0.89 & 0.14 & 0.85 \\
4.Presentation of question prompts & 3.69 & 0.77 & 3.72 & 0.92 & 0.04 & 0.25 \\
5.Question prompts for learning & 3.59 & 0.92 & 3.67 & 1.04 & 0.07 & 0.43 \\
6.Question prompts in US100 & 3.56 & 0.96 & 3.68 & 1.02 & 0.12 & 0.69 \\
7.Time for Guideline & 7.13 & 12.74 & 6.45 & 6.92 & -0.10 & -0.38 \\
\hline
\end{tabular}

Note: The Seminar group, n2=69, The Online Learning Group, n1=64.

Table 4.3-2 Comparisons between the seminar group and the online learning with e-mailed prompts group in satisfaction after intervention

\begin{tabular}{lllllll}
\hline & \multicolumn{7}{l}{ Online learning with } \\
prompts & \multicolumn{5}{c}{ Seminar } & \\
\cline { 2 - 6 } Factors & M1 & SD1 & M2 & SD2 & Effect size & t \\
\hline 1.Importance of question prompts & 3.80 & 1.01 & 3.77 & 0.91 & -0.04 & -0.17 \\
2.Usefulness of question prompts & 3.76 & 0.93 & 3.74 & 0.95 & -0.02 & -0.09 \\
3.Materials'organization & 3.71 & 0.99 & 3.78 & 0.89 & 0.08 & 0.40 \\
4.Presentation of question prompts & 3.78 & 0.88 & 3.72 & 0.92 & -0.06 & -0.31 \\
5.Question prompts for learning & 3.62 & 1.07 & 3.67 & 1.04 & 0.04 & 0.22 \\
6.Question prompts in US100 & 3.67 & 1.00 & 3.68 & 1.02 & 0.01 & 0.07 \\
7.Time for Guideline & 6.09 & 8.05 & 6.45 & 6.92 & 0.05 & 0.25 \\
\hline
\end{tabular}

Note: Seminar Group, n2=69, Online Learning with E-mailed Prompts Group, n1=45.

\subsection{Preferred approach to scaffolding creative problem solving}

The results from survey on preferred instruction approach to scaffolding creative problem solving are tabulated Table $4.3-3$. Those results shown that $51 \%$ of students in the intervention groups prefer the "seminar", when they were asked with the survey question: "Which is the best approach to deliver the strategies for your self-regulated learning and creative problem solving among the given following approaches”. The data shows that seminar approach might be favored by most students in intervention group, and may imply that students like to take the seminar or lecture approach to learning creative problem strategies from instructors even though they may learn from the online materials.

To respond to the survey question: which is the suitable format to deliver the strategies for your self-regulated learning and creative problem solving between the given following two formats, 54\% of students in the intervention groups favorite the query format of prompts. The results indicate that question prompts may be considered effective and widely accepted by majorities of students in intervention group. 
Table 4.3-3 Approach of learning prompts and presenting format of question prompts

\begin{tabular}{|c|c|c|c|c|}
\hline Item & & Control group & Intervention group & Total \\
\hline \multirow{6}{*}{ Delivery approach } & Seminar & 17 & 91 & 108 \\
\hline & & $41 \%$ & $51 \%$ & $49 \%$ \\
\hline & Online learning & 18 & 53 & 71 \\
\hline & & $44 \%$ & $30 \%$ & $32 \%$ \\
\hline & Online learning with prompts & 6 & 34 & 40 \\
\hline & & $15 \%$ & $19 \%$ & $18 \%$ \\
\hline Total & & 41 & 178 & 219 \\
\hline \multirow{4}{*}{ Delivery formats } & A. Statement (Definition) & 23 & 80 & 103 \\
\hline & & $56 \%$ & $45 \%$ & $46 \%$ \\
\hline & B. Question Prompt (Query) & 17 & 96 & 113 \\
\hline & & $41 \%$ & $54 \%$ & $52 \%$ \\
\hline Total & & 40 & 176 & 219 \\
\hline
\end{tabular}

\subsection{Correlation Analysis of question prompts and relevant learning variables}

By coding available students' learning process journals and final project reports based on rubrics presented in the previously published ASEE paper by Zheng et al. ${ }^{20}$, the extent to which students use question prompts, and variables of their learning process and learning outcome can be obtained in a quantitative manner. Those process and outcome variables are defined in the previously published ASEE paper by Zheng et al. ${ }^{20}$ and shown in Table 4.4 and. Table 4.4 presents results of the correlation analysis of those variables obtained from students' learning journals and final project reports collected in 2013 implementation.

As shown in Table 4.4 below, question prompts were related with learning process $(\mathrm{r}=0.871, \mathrm{p}<0.01)$. The prompts were closely related with three components of self-regulated learning, involving "self-monitoring” ( $\mathrm{r}=0.620, \mathrm{p}<0.01)$, "motivation interest” $(\mathrm{r}=0.841$, $\mathrm{p}<0.01)$ and "time planning" $(\mathrm{r}=0.822, \mathrm{p}<0.01)$. The prompts were also correlated with three components of creative thinking process, including "idea generation" $(r=0.396, p<0.01)$, "seeking help" ( $r=0.487, \mathrm{p}<0.01)$, and "problem identification” $(r=0.697, \mathrm{p}<0.01)$. These results indicate that question prompts are effective in promoting students self-regulated learning and creative thinking in learning process. Furthermore, the question prompts were also correlated with learning outcomes $(\mathrm{r}=0.616, \mathrm{p}<0.01)$. The prompts were related with components of creative problem solving, such as "innovative solution" ( $(\mathrm{r}=0.505, \mathrm{p}<0.01)$, "strategies utilized" ( $r=0.331, \mathrm{p}<0.05)$, and "alternative solutions" $(\mathrm{r}=0.348, \mathrm{p}<0.05)$. The prompts were also correlated with the quality of work, such as "proper presentation" $(\mathrm{r}=0.610, \mathrm{p}<0.01)$ and "problem description" $(\mathrm{r}=0.653, \mathrm{p}<0.01)$. The analysis also showed that learning outcome were related with learning process $(r=0.550, p<0.01)$. The components of learning outcome were significantly related with learning process $(0.547<\mathrm{r}<0.947$, $\mathrm{p}<0.01)$. This means that the better scores of the process of community service learning, the better the learning outcomes is. Those results demonstrated the similar correlation as those 
obtained in the previous implementation as reported in the previously published ASEE paper by Zheng et al. ${ }^{20}$ 
Table 4.4 Correlations among students' process of learning, those in their learning outcomes in design project and question prompts ( $\mathrm{n}=50$ )

\begin{tabular}{|c|c|c|c|c|c|c|c|c|c|c|c|c|c|c|c|c|c|}
\hline Variables & Dimension & 1 & 2 & 3 & 4 & 5 & 6 & 7 & 8 & 9 & 10 & 11 & 12 & 14 & 15 & 16 & 18 \\
\hline \multirow{10}{*}{$\begin{array}{l}\text { Learning } \\
\text { Process }\end{array}$} & \begin{tabular}{|l|} 
1.Motivation \\
interest
\end{tabular} & 1 & & & & & & & & & & & & & & & \\
\hline & \begin{tabular}{|l|} 
2.Problem \\
identification \\
\end{tabular} & $.554^{* *}$ & 1 & & & & & & & & & & & & & & \\
\hline & 3.Time planning & $.724^{* *}$ & $.646^{* *}$ & 1 & & & & & & & & & & & & & \\
\hline & $\begin{array}{l}\text { 4.Relevant } \\
\text { strategies }\end{array}$ & .068 & .201 & $.354^{*}$ & 1 & & & & & & & & & & & & \\
\hline & 5.Idea-generation & $.479 * *$ & $.315^{*}$ & $.326^{*}$ & -.138 & 1 & & & & & & & & & & & \\
\hline & 6.Self-monitoring & $.565^{* *}$ & $.591^{* *}$ & $.617^{* *}$ & .024 & $.603^{* *}$ & 1 & & & & & & & & & & \\
\hline & 7.Self-evaluation & -.032 & $.369 * *$ & .256 & $325 *$ & -.261 & .206 & 1 & & & & & & & & & \\
\hline & 8.Seeking help & $.478^{* *}$ & $.509 * *$ & $.551^{* *}$ & 249 & .158 & .189 & $.283^{*}$ & 1 & & & & & & & & \\
\hline & \begin{tabular}{|l} 
9.Creative \\
thinking \\
\end{tabular} & $-.302^{*}$ & -.207 & -.095 & .056 & -.074 & $-.302^{*}$ & -.064 & -.121 & 1 & & & & & & & \\
\hline & 10.Total process & $.800^{* *}$ & $.806^{* *}$ & $.889^{* *}$ & $331^{*}$ & $.558^{* *}$ & $.762 * *$ & $.299^{*}$ & $.634^{* *}$ & -.172 & 1 & & & & & & \\
\hline \multirow{6}{*}{$\begin{array}{l}\text { Learning } \\
\text { outcomes }\end{array}$} & $\begin{array}{l}\text { 11.Proper } \\
\text { presentation }\end{array}$ & $.562^{* *}$ & $.510^{* *}$ & $.390 * *$ & $320^{*}$ & .168 & .162 & .260 & $491^{* *}$ & .016 & $.547^{* *}$ & 1 & & & & & \\
\hline & $\begin{array}{l}\text { 12.Problem } \\
\text { description }\end{array}$ & $.635 * *$ & $.487 * *$ & $.517^{* *}$ & $.279 *$ & .200 & $.340^{*}$ & .198 & $.430^{* *}$ & .013 & $.610^{* *}$ & $.932 * *$ & 1 & & & & \\
\hline & $\begin{array}{l}\text { 14.Innovative } \\
\text { solution }\end{array}$ & $.608^{* *}$ & .276 & $.368^{* *}$ & -.020 & $.676^{* *}$ & $.332 *$ & $-.293^{*}$ & .055 & .102 & $478^{* *}$ & $.613^{* *}$ & $685^{* *}$ & 1 & & & \\
\hline & $\begin{array}{l}\text { 15.Alternative } \\
\text { solutions } \\
\end{array}$ & $.490^{* *}$ & .170 & .234 & .201 & $684^{* *}$ & .196 & $-.411 * *$ & -.097 & .119 & $.310^{*}$ & $.410^{* *}$ & $.459 * *$ & $.947^{* *}$ & 1 & & \\
\hline & $\begin{array}{l}\text { 16.Strategies } \\
\text { utilized }\end{array}$ & $425^{* *}$ & .003 & .114 & $-395^{* *}$ & $.529 * *$ & .219 & -.159 & -.075 & .077 & .203 & $.496^{* *}$ & $.534^{* *}$ & $.807^{* *}$ & $.801^{* *}$ & 1 & \\
\hline & $\begin{array}{l}\text { 18.Total } \\
\text { outcomes } \\
\end{array}$ & $.649 * *$ & $.413^{* *}$ & $.418^{* *}$ & .106 & $.434^{* *}$ & $.282 *$ & .010 & $.292 *$ & .059 & $.550^{* *}$ & $.898^{* *}$ & $.918^{* *}$ & $.886 * *$ & $.744 * *$ & $.766^{* *}$ & 1 \\
\hline $\begin{array}{l}\text { Question } \\
\text { prompts } \\
\end{array}$ & $\begin{array}{l}\text { 19.Question } \\
\text { prompts }\end{array}$ & $.841^{* *}$ & $.697^{* *}$ & $.822 * *$ & .241 & $.396^{* *}$ & $.620^{* *}$ & .162 & $.487 * *$ & .003 & $.871^{* *}$ & $.610 * *$ & $.653 * *$ & $.505^{* *}$ & $.348^{*}$ & $.331^{*}$ & $.616 * *$ \\
\hline
\end{tabular}




\section{Summary and discussion of results}

The correlation analysis of data collected from of the implementation in 2012 demonstrated the effectiveness of question prompts to improve students' learning process and learning outcomes ${ }^{20}$. The data collected from the implementation in 2013 further confirm this correlation. Based on the results presented in this paper, the following discussions are made on how different interventions through question prompts might impact students' perception on their skill development and their learning experience.

The data analysis results indicate that with interventions, students in intervention groups became more confident in their own creativity and intelligence. This may be a result of the increase of students' self-awareness of their own creativity or intelligence, which agrees with Gokhale and O'Dea's finding that students in PBSL showed the increased self-confidence and self-esteem ${ }^{21}$.

Comparison among different intervention group shows that the students in the seminar group did not think they gained more knowledge of creative methodology and strategies, and they believed more in fixed intelligence and perceived less importance of creativity. The students in online leaning group (Group C) and the online learning with e-mailed prompts group (Group D) reported their gain in creativity and creative methodology and strategies. The students in Group D even demonstrated the increase in utilizing creativity strategies. It also should be noted that students in Group D did not show more increase in their confidence of being a creative person and knowing about creativity, which is different from those in Group C. This result might be explained by the other reported factors that students in Group $\mathrm{D}$ enjoyed very high scores in the items of "creative person"(4.00) and "knowing about creativity"(4.23). In addition, students in Group D also gained more in creative methodology and strategies (effect size $=0.77$ ) than those in Group C (effect size $=0.37$ ). This suggest that students in Group D might recognize more on the importance of the creative methodology and strategies and feel that they still lack enough knowledge, leading to the decrease in their belief of being a creative person and knowing about creativity.

Compared with the seminar group, both Group C and D demonstrated increase in students' recognition of career identity and their perception of the positive influence of increased creativity on their academic performance. The only difference is Group D enjoyed significant growth, while Group C displayed slight increase. The seminar group displayed slight increase in confidence and application of cognitive strategies and question prompts. This indicates that online learning interventions were more effective in enhancing students' career identity, while seminar could enhance student's self-confidence and strategy application. Furthermore, the comparison of the effective size in survey items between Group $\mathrm{C}$ and $\mathrm{D}$ shows that the online learning with e-mailed prompts was more effective in enhancing students' self-efficacy and creativity.

The satisfaction survey demonstrated that the students in seminar group were more satisfied with question prompts and the delivery method than Group C, but less in those survey items than Group D, in which instructors or facilitators sent e-mails to students to remind them of question prompts. This indicates that the scaffolding through the question prompts is necessary for students. This result is verified by the facts that $51 \%$ of students in intervention groups chose the seminar as the preferred delivery approach, and that $54 \%$ of intervention group students chose the question prompts as the preferred delivery format. Those facts indicate that students may need the instructor's explanation on the scaffolding 
and prefer the format of question prompts to facilitate their learning not just facts as statements.

Compared with the result from the first implementation in 2012, the trend of growth in the intervention groups in 2013 is almost the same. Students showed significant higher scores in the perception of "learned creativity in class" and lower scores in "creativity improved". The significant decrease in the perception of "creativity improved" might result from the increased belief in "fixed intelligence".

\section{Conclusions}

Results from analysis of available data collected from two rounds of implementing the presented scaffolding framework indicate that scaffolding creative problem solving through freshmen's project-based service learning may enhance student's self-efficacy and their interest in engineering, and promote their learning and application of strategies for creative problem solving. The scaffolding delivered through online learning materials with e-mailed prompts seems to be the most effective method in strengthening students' interest in engineering, magnifying their self-efficacy, and promoting their methodology learning. The scaffolding delivered through seminar (or traditional lecture) may help students apply cognitive strategies and questions prompts and enhance their confidence.

\section{Acknowledgements}

The authors gratefully acknowledge the support of the National Science Foundation under the grant NSF/HRD \# 1036328. Any opinions, findings, conclusions, or recommendations expressed in this material are those of the authors and do not necessarily reflect the views of the National Science Foundation. The authors thank the participating instructors of the Course University Success 100 for their contribution of assisting implementing the presented instructional framework. Authors also thank graduate students Ms. Haiyan Zhou and Mr. Yujing Nie for their assistance in collecting students' learning data and input them in an organized format.

\section{Reference:}

1. Schunn, C. D., Paulus , P. B., Cagan, J., and Wood, K. (2006). “The Scientific Basis of Individual and Team Innovation and Discovery”. Final report from the NSF innovation and discovery workshop. Retrieved from http://www.nsf.gov/pubs/2007/nsf0725/nsf0725.pdf

2. Burleson, W. (2005). "Developing Creativity, Motivation, and Self-actualization with Learning Systems”. International Journal of Human-Computer Studies, 63: 4-5.

3. Torrance, E.P. (1965). Rewarding Creative Behavior: Experiments in Classroom Creativity. Englewood Cliffs, NJ: Prentice-Hall, Inc.

4. Amabile, T. (1998). "The Social Psychology of Creativity: A Componential Conceptualization”. Journal of Personality and Social Psychology 45(2), (1983): 357-376; Amabile, T. M. "How to Kill Creativity”. Harvard Business Review, 76(5), 76-87. 
5. Flavell, J. H. (1981). “Cognitive Monitoring”. In W. P. Dickson (Ed.), Children’s Oral Communication Skills.New York: Academic Press.

6. Dunslosky, J., \& Thiede, K. W. (1998). "What Makes People Study More? An Evaluation of Factors that Affect Self-paced Study”. Acta Psychologica, 98, 37-56.

7. Brown, A. L. (1987). "Metacognition, Executive Control, Self Regulation and other More Mysterious Mechanisms.” In F. E. Weiner \& R. H. Kluwe (Eds.), Metacognition, Motivation, and Understanding.Hillsdale, NJ: Erlbaum.

8. Nietfeld, J. L., \& Schraw, G. (2002). "The Effect of Knowledge and Strategy Explanation on Monitoring Accuracy”. Journal of Educational Research, 95, 131-142.

9. White, B. Y., \& Frederiksen, J. R. (1998). “Inquiry, Modeling, and Metacognition: Making Science Accessible to All Students”. Cognition \& Instruction, 16: 3-118.

10. Ogot, M. and Okudan, G. E. (2005). "Integrating Systematic Creativity into First-year Engineering Design Curriculum”. International Journal of Engineering Education, 2.

11. Ocon, R. (2006). “Teaching Creative Thinking to Engineering and Technology Students”. Proceeding of $9^{\text {th }}$ International Conference on Engineering Education.

12. Yashin-Shaw, I., ( 2003).“The effectiveness of the StrateGEE model for creative problem-solving as a tool for facilitating creative thinking”, in Enriching learning cultures: proceedings of the 11th annual international conference on post-compulsory education and training: volume 3., ed. G University Faculty of Education Centre for Learning Research, Australian Academic Press, Brisbane, pp.190-197.

13. Cropley, D. (2005). "Engineering Creativity: A Systems Concept of Functional Creativity”. In Kaufman, James C. \& Baer, John (Eds). Creativity Across Domains: Faces of the Muse. Mahwah, NJ: Lawrence Erlbaum Associates Publishers 169-185.

14. Magee, C. L. et al. (2003). "Advancing Inventive Creativity through Education, the report of the LemelsonMIT Workshop on Advancing Inventive Creativity through Education”. Retrieved in 2014, http://web.mit.edu/invent/n-pressreleases/downloads/education.pdf.

15. Barak, M. \& Goffer, N. (2002). “Fostering Systematic Innovative Thinking and Problem Solving: Lessons Education Can Learn from Industry”. International Journal of Technology and Design Education, 12(3), 227247.

16. Wirth,J., (2009). “Prompting self-regulated learning through prompts.” Zeitschrift für Pädagogische Psychologie, 23(2), 91-94.

17. Rosenshine, B., \& Meister, C. (1992). "The Use of Scaffolds for Teaching Higher-level Cognitive Strategies”. Educational Leadership, 49(7), 26-33.

18. Davis, E. A., Linn, M. C. (2000). “Scaffolding Students' Knowledge Integration: Prompts for Reflection in KIE”. International Journal of Science Education, 22(8), 819-37.

19. McCormick, M., Swan, C., Matson, D., Gute, D., \& Durant, J. (2008). "Enhancing Engineering Education: Learning to Solve Problems through Service-learning Projects.” Retrieved from http://search.asee.org/search/fetch?url=file\%3A\%2F\%2Flocalhost\%2FE\%3A\%2Fsearch\%2Fconference\%2F17 \%2FAC\%25202008Full1946.pdf\&index=conference_papers\&space=129746797203605791716676178\&type=a pplication\%2Fpdf\&charset=

20. Zheng ,W., Wang, L.S. and Yin, J.J., (2013). “Correlation Analysis of Scaffolding Creative Problem Solving Through Question Prompts with Process and Outcomes of Project-Based Service Learning.” 
Proceedings of 2013ASEE Annual Conference \& Exposition, Paper number: AC 2013-6169, Atlanta, Georgia, June 23 - 26, 2013

21. Gokhale, S. and O’Dea, M., (2000). "Effectiveness of Community Service in Enhancing Student Learning and Development.” Proceedings of 2013ASEE Annual Conference \& Exposition, St. Louis, Missouri, June 1821, 2000. 